experts are now warning that biologists need to engage more seriously with the dual-use issue. The prospect of a deliberate release of dangerous biological material is of increasing concern, whether through lab break-ins or by research personnel. The failed terrorist attacks in July in central London and at Glasgow airport seemed even more shocking when it emerged that many of the suspects were doctors. "People can't just walk in off the street into labs, but if there was somebody who wished to do with bioagents what was done with these other things we'd have a job to safeguard against it," says Plumb.

\section{Regulate or be regulated}

National and international regulators are currently looking at whether lab safeguards are adequate and how rigorously they are applied. "Biosecurity is probably still a little bit too lax," said Jens Kuhn, a virologist at Harvard Medical School who advises on arms control.

In the United States, the most stringent regulations apply to labs working with 'select agents', which include Ebola virus, saxitoxin (a lethal toxin found in algae), foot-and mouth-disease virus and bird flu, are required to adhere to a stringent set of rules. Suggestions for site security in the rules include guard services, gated entry, biometric readers and locked storage units. In addition, inventory control and IT systems must be assessed.

However, the US Department of Health and Human Services (DHHS), which is responsible for regulating many dangerous materials, has identified "serious weaknesses" in the security of select agents in university laboratories. These problems were initially identified after a review of 11 universities in 2002. A followup investigation of 15 universities in 2004, the results of which were released last year, identified problems with 11 that "could have compromised the ability to safeguard select agents from accidental or intentional loss".

Access controls, such as procedures for issuing electronic keys to sensitive areas, were problematic at six universities. Training for individuals with access to dangerous agents had either not been provided or not been documented at three universities. Inventory and access records were also a problem, with some records incomplete or "difficult to decipher".

Contacted by Nature, the DHHS insisted that all the weaknesses had been corrected. But the number of problems identified raises questions about the integrity of labs in general and biology labs in particular.

"It's fair to say that unlike areas such as physics, biologists haven't had that kind of discussion in recent years," says Brian Rappert, a biosecurity expert at the University of Exeter, UK.

Rappert has been running seminars on biosecurity with Malcolm Dando, professor of international security at the University of Bradford, UK. They found that biosecurity awareness among the 1,600 biologists who attended their seminars was extremely low. "Our regular finding was that very few of them had thought very much about these dual-use issues," says Dando

This lack of engagement with security may come back to haunt biologists as the trend towards regulation accelerates. Reynolds Salerno, manager of the International Biological Threat Reduction programme at the US government's Sandia National Laboratories in Albuquerque, New Mexico, points out that the international community is beginning to consider the possibility that malicious individuals might acquire dangerous pathogens or toxins from a legitimate laboratory. "The biotechnology community does need to be more involved in helping government establish the risk of dual-use technology and at least provide cogent arguments not to over-regulate these new technologies," he told Nature.

Next year, countries including Britain, China, Germany and the United States will revisit the international Biological and Toxin Weapons Convention,
re than 150 countries are signatories. "One of the questions is the whole issue of biosafety and oversight, awareness, codes of conduct," says Dando. "We'll see increasing attention from scientific bodies in the run up to that."

Europe is also looking at biosecurity. In July, the European Commission released a consultation paper on bio-preparedness, noting that "in some domains imperfect implementation of safety measures and the existence of security gaps may continue to pose a risk". Proposals on the cards include limiting the number of security-cleared researchers and accredited labs, mandatory courses on biosafety at university level and obliging researchers to adopt a professional code of conduct.

With regulation already a burden, many researchers fear that more rules could be stifling. "The more security you have, the more impaired the research gets. It's definitely very difficult and gets more difficult by the year," says Kuhn. "In the US, in general the people who make these regulations don't consult with the scientists. Whereas physicists have been dealing with these issues for a very long time and have shown research can continue very successfully, biologists just see another hurdle in their grant writing, more paperwork and their papers disappearing. They get panicky."

Daniel Cressey

\section{ZOONEWS}

\section{Croc on the run}

Emergency workers in Ukraine are hunting a crocodile named Godzilla that escaped from a circus. Pity the local guinea-pigs: newspaper reports say the furry critters will be used as bait.

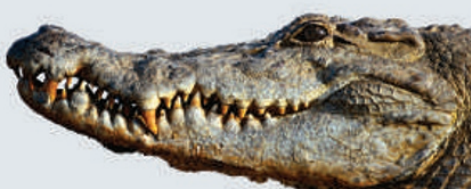

\section{SCORECARD}

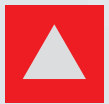

'Liposuction' for pits Forget antiperspirant, excessive underarm sweat can be reduced to a damp memory by use of a technique that sucks out the sweat glands.

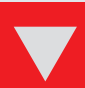

Liposuction is the pits It's now 'normal' to be obese according to a study that shows American women have become fatter since it's become more socially acceptable to carry extra weight.

\section{ON THE RECORD}

\section{“Even if it has Velcro on it, you set it aside and within 30 seconds it's gone and you have no idea where it went to. So we'll be playing some treasure hunts."}

Teacher-turned-astronaut Barbara Morgan describes the challenges of her trip to the International Space Station, along with her 10 million cinnamon basil seeds.

\section{ROBOT NEWS}

So you think you can dance Researchers have recruited a prancing dancebot to keep traditional dance alive. So far it has learned the aizu bandaisan - a Japanese folk dance - but Sidelines wants to see it do the Time Warp. It's just a jump to the left...

Sources: BBC, J. Am. Acad. Dermatol., Florida State Univ., NASA, New Scientist Reuters

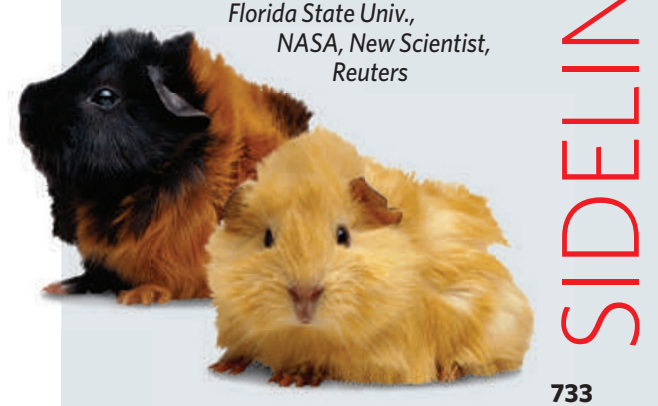

